\title{
O processo de cicatrização influenciado pelo hipotireoidismo e pelo envelhecimento. Estudo da cicatrização da parede abdominal, em ratos
}

\author{
Maria de Lourdes Pessole Biondo-Simões ${ }^{2}$, Sergio Ossamu Ioshiii ${ }^{3}$, Karin Soldatelli Borsato ${ }^{4}$, Elise Zimmermann ${ }^{5}$
}

Biondo-Simões MLP, Ioshii SO, Borsato KS, Zimmermann E. O processo de cicatrização influenciado pelo hipotireoidismo e pelo envelhecimento. Estudo da cicatrização da parede abdominal, em ratos. Acta Cir Bras [serial on line] Available from: URL: htt:// www.scielo.br/acb.

RESUMO - Objetivo: O hipotireoidismo é uma situação bastante comum nos indivíduos idosos e influencia a síntese protéica. O presente estudo busca conhecer a influência do hipotireoidismo no processo de cicatrização de ratos idosos. Método: Utilizaram-se 96 ratos Wistar, machos; 48 deles com média de idade de 110 dias e 48 com 760 dias. Metade dos animais jovens e metade dos velhos eram eutireoideanos e metade eram hipotireoideanos. Conseguiu-se o hipotireoidismo por meio de tireoidectomia total. Após 30 dias, fez-se uma laparotomia mediana seguida de laparorrafia com 2 planos de síntese. No 3. ${ }^{\circ}$ 7. ${ }^{\circ}$ e $14 .{ }^{\circ}$ dias de pós-operatório, sorteados, 6 animais de cada grupo, foram submetidos à eutanásia. Fez-se a análise macroscópica, da resistência e histopatológica. Resultados: A resistência das cicatrizes da pele, foi menor nos animais hipotireoideanos, tanto jovens ( $\mathrm{p}=0,0145$ ), quanto velhos ( $\mathrm{p}=0,0242$ ), não se encontrando relação significante com a idade. A resistência das cicatrizes do plano peritônio-músculo-aponevrótico,foi menor nos animais velhos, no $14 .^{\circ}$ dia $(\mathrm{p}=0,0014)$ e ainda menor quando eram velhos e hipotireoideanos $(\mathrm{p}=0,0000)$. A evolução histológica foi semelhante, entretanto, existiram diferenças quanto à presença de colágeno. No 7. dia as cicatrizes cutâneas apresentavam menor conteúdo de colágeno nos animais hipotireoideanos, jovens $(\mathrm{p}=0,0201)$ e velhos $(\mathrm{p}=0,0003)$. No $14{ }^{\circ}$ dia as cicatrizes dos velhos hipotireoideanos tinham menos colágeno do que as dos velhos normais $(\mathrm{p}=0,0092)$ e menos do que as dos jovens hipotireodeanos $(\mathrm{p}=0,0283)$. No plano peritônio-músculo-aponevrótico, no $3{ }^{\circ}$ dia, as cicatrizes dos animais hipotireoideanos apresentavam menos colágeno do que as dos controle normais, tanto jovens ( $\mathrm{p}=0,0089)$ quanto velhos ( $\mathrm{p}=0,0171)$, mas não havia relação com a idade. Esta associação se manteve nas avaliações do 7. e do 14. dia, porém nestes tempos observou-se dependência da idade. Conclusão: A análise dos resultados permite concluir que existe prejuízo da cicatrização na presença de hipotireoidismo que é piorada com o envelhecimento.

DESCRITORES: Cicatrização. Colágeno. Hipotireoidismo. Envelhecimento.

\section{Introdução}

A realização de procedimentos cirúrgicos em pacientes idosos é acompanhada da preocupação de médicos e familiares quanto às complicações. Muitos cirurgiões acreditam que a idade avançada produza mudanças fisiológicas intrínsecas que resultam em dano à cicatrização.

Vários autores descreveram deficiências da cicatrização e mesmo deiscências em pacientes idosos ${ }^{1-4}$.

Não se pode esquecer que indivíduos idosos, muitas vezes, apresentam-se com doenças cardiovasculares, diabetes ou neoplasias. Não é incomum encontrarem-se com desnutrição, deficiências vitamínicas, alterações neuroendócrinas e utilizando medicamentos, os mais variados, e que estas situações podem ser responsáveis por distúrbios da reparação tecidual.

Pesquisadores descreveram, em idosos, atraso da reepitelização e demonstraram diminuição do colágeno $\mathrm{I}^{5,6}$.
Em estudos experimentais, feitos em ratos e camundongos, foi confirmado atraso da síntese dos colágeno tipo I e III ${ }^{7,8}$. Cristofalo e Pignolo ${ }^{9}$ mostraram que fibroblastos senescentes são incapazes de responder a estímulos mitogênicos. Mais recentemente, Kletsas et al ${ }^{10}$ afirmaram que não existem evidências da relação de dependência da idade no declínio da resposta de fibroblastos humanos aos vários fatores de crescimento. Para eles a capacidade de sintetizar esta mantida e as alterações estariam na dependência de fatores sistêmicos, como os níveis de hormônios.

Deficiências de cicatrização têm sido descritas em pacientes com hipotireoidismo grave resultante de tireodectomia total ou de radioterapia sobre o pescoço ${ }^{11,12}$. Segundo estes autores, os mecanismos através dos quais a disfunção tireoideana enfraquece a cicatrização, são múltiplos. Sabe-se que proteínas e fontes de energia são necessárias para que ocorra a cicatrização e é conhecido que a administração de hormônio

1. Estudo desenvolvido na Pontifícia Universidade Católica do Paraná.

2. Professora Titular de Técnica Operatória - Metodologia Científica da PUCPR e Coordenadora da Disciplina de Técnica Cirúrgica e Cirurgia Experimental da Universidade Federal do Paraná, Doutora em Cirurgia Experimental pela UNIFESP-EPM, Titular CBC-PR.

3. Professor de Patologia Experimental da UFPR e da PUCPR.

4. Professora Responsável pelo Laboratório de Ensaios Destrutivos da PUCPR.

5. Aluna do Programa de Iniciação Científica da PUCPR. 
tireoideano à animais com hipotireodismo, induz à síntese de ácidos nucléicos e de proteínas, além de elevar a fosforilação oxidativa das mitocôndrias ${ }^{13}$.

Já em 1967 autores afirmavam que, no hipotireoidismo, a síntese de colágeno estava comprometida e consideraram que ratos com hipotireoidismo apresentavam biossíntese, solubilidade e metabolismo do colágeno diminuídos ${ }^{4,14}$.

Yao e Eghbali ${ }^{15}$ descreveram em modelo experimental, em camundongos, envolvimento direto do hormônio tireoideano na modulação da expressão do gen para o colágeno I e Lee et $\mathrm{al}^{16}$ identificaram mecanismos moleculares envolvidos na indução do hormônio tireodeano regulando o RNA mensageiro para o colágeno I. O hipotireoidismo levava à inibição da síntese do colágeno, mostrado pela falta de fibrose induzindo à hipertrofia ventricular esquerda e baixa concentração do colágeno intracelular nos fibroblastos cardíacos.

Um estudo experimental feito em ratos com hipotireoidismo induzido com 5-propul,2-thiuracil, demonstrou diminuição da resistência das cicatrizes abdominais $(p<0,001)$ e da concentração de hidroxiprolina $(\mathrm{p}<0,001)$, apenas nas observações do $14 .^{\circ}$ dia. Neste estudo observaram não só diminuição da concentração de colágeno mas também atraso da organização ${ }^{17}$.

Relatou-se atraso na reparação de fraturas quando da existência de hipotireoidismo ${ }^{(18)}$. Além da diminuição do colágeno $\mathrm{IV}^{19}$. Este fato foi posteriormente verificado, em ratos, nos quais foi constatada baixa concentração de hidroxiprolina e de colágeno $\mathrm{IV}^{20}$.

Natori et $\mathrm{al}^{20}$ descreveram em feridas abdominais de ratos com hipotireoidismo cirúrgico, importante diminuição da concentração de hidroxiprolina no $7 .^{\circ}$ dia $(p<0,05)$ e no $14 .^{\circ}$ dia $(\mathrm{p}<0,01)$ com importante declínio do colágeno IV em todos os tempos $(\mathrm{p}<0,02)$. O hormônio tireoideano estaria associado com a proliferação e a secreção dos fibroblastos. A supressão da secreção dos hormônios tireoideanos causaria distúrbio da ativação metabólica nos tecidos e na síntese do colágeno, se extendendo da fase inflamatória até a fase proliferativa. Sugeriram que o hormônio tireoideano estaria associado com a proliferação e a secreção dos fibroblastos.

O envelhecimento determina reações que alteram o "status" tireoideano, sendo relativamente freqüente, o estado de hipotireoidismo. Oliveira ${ }^{21}$ relatou que $24,1 \%$ dos pacientes idosos por ela estudados em seu trabalho de tese apresentavam hipotireoidimo e Schindler ${ }^{22}$ salientou que o avançar da idade aumenta a possibilidade de hipofunção tireoideana, especialmente nas mulheres. Segundo este autor após a menopausa $2,4 \%$ das mulheres apresentam clínica de disfunção e 23,2\% têm doença subclínica.

Em estudo de nossa linha de pesquisa observou-se que, embora existam diferenças no processo de cicatrização de jovens e velhos, a idade, por si só, não é a causa da falência da cicatrização, tanto nas feridas da parede abdominal, quanto nas das anastomoses colônicas ${ }^{23}$. É provável que distúrbios relacionados com o envelhecimento sejam responsáveis pelos danos causados à reparação. Como o hipotireoidismo é uma situação bastante comum nos indivíduos idosos, e o "status" tireoideano influencia a síntese proteica, passamos a desenvolver o presente estudo com a finalidade de conhecer a influência do hipotireoidismo no processo de cicatrização de ratos idosos.

\section{Métodos}

Para o desenvolvimento deste estudo foram respeitadas as orientações do Colégio Brasileiro de Experimentação Animal (COBEA) e as determinações da Lei Federal 6.638.

Foram utilizados no experimento 96 ratos machos, Rattus norvegicus albinus, Rodentia mammalia, da linhagem Wistar. Destes 48 eram animais adultos jovens com idade média de 110 dias e 48 eram animais velhos, com idade média de 760 dias. O grupo jovem pesou em média 239,93 $\pm 18,78$ gramas (\% do desvio padrão $=7,80$ ) e o dos velhos $361,06 \pm 39,34$ gramas $(\%$ do desvio padrão $=10,89)$. Metade dos animais jovens e metade dos animais velhos eram normais e metade hipotireoideanos. Desta forma conseguiu-se 4 grupos: jovens normais, jovens hipotireoideanos, velhos normais e velhos hipotireoideanos.

Sob anestesia obtida com $0,1 \mathrm{ml} / 100 \mathrm{~g}$ de peso do animal de uma mistura de $1 \mathrm{ml}$ de quetamina $(50 \mathrm{mg}$ ) com $1 \mathrm{ml}$ de xilazina $2 \%(20 \mathrm{mg})$ se fez a tireoidectomia total nos animais que deveriam ser induzidos ao estado de hipotireoidismo e cervicotomia exploradora, sem tireoidectomia nos que seriam controles eutireoideanos. Após a recuperação anestésica estes animais, marcados, foram mantidos em gaiolas apropriadas para a espécie, no ambiente do biotério, com temperatura de $20^{\circ} \pm 2^{\circ} \mathrm{C}$, ciclo claro/escuro de 12 horas e umidade do ar a própria do ambiente. Todas as caixas foram colocadas em prateleiras à igual distância da fonte de luz. Receberam ração padrão comercial e água suplementada de cálcio.

Após 30 dias, foram novamente anestesiados e pesados. Se fez uma incisão mediana de $4 \mathrm{~cm}$ seguida da laparorrafia com dois planos de síntese, o primeiro peritônio-músculoaponevrótico e o segundo o da pele, com sutura contínua de fio monofilamentar de náilon 4.0.

No $3 .^{\circ}, 7 .^{\circ}$ e $14 .^{\circ}$ dia de pós-operatório, escolhidos por sorteio, 6 animais de cada grupo foram submetidos à eutanásia com dose letal de éter etílico. A análise macroscópica teve por objetivo avaliar, na parede abdominal, a existência de deiscências e hérnias.

Fez-se a ressecção de um retalho da parede abdominal que continha a cicatriz da pele e de outro que continha a cicatriz do plano peritônio-músculo-aponevrótico. Desprezadas as extremidades, dividiu-se o restante da cicatriz destinando-se um segmento para o estudo da resistência e o outro para o anátomo-patológico. 
As cicatrizes da parede abdominal tiveram a resistência avaliada em ensaio tensiométrico em máquina de tração EMICâ do Laboratório de Análises Destrutivas da PUCPR. Considerou-se força máxima a maior força ou carga aplicada no corpo de prova até sua ruptura. Aplicaram-se as forças, sempre perpendicularmente à cicatriz, tentando afastar suas bordas.

As peças foram enviadas para o Laboratório de Patologia Experimental da PUCPR para a confecção de lâminas. Os cortes histológicos foram corados pela Hematoxilina-eosina para identificação dos aspectos gerais e pela técnica do Sirius-red para a identificação dos colágenos I e III $^{24}$.

Examinaram-se os cortes histológicos corados pelo Sirius-red em microscópio, utilizando-se fonte de luz polarizada. As fibras colágenas mais espessas e fortemente birrefringentes apresentam-se coradas de tons de laranja a vermelho e representam o colágeno I, enquanto as fibras mais finas e dispersas, fracamente birrefringentes se apresentam coradas de verde e representam o colágeno III. As imagens captadas por uma câmara Sony ${ }^{\circledR}$ CCD 101, enviadas a um monitor Sony Trinitron ${ }^{\circledR}$ colorido, congeladas e digitalizadas por uma placa digitalizadora Oculus ${ }^{\circledR}$ TCX (coreco), foram analisadas pelo aplicativo Image Plus 4.5 para Windows em computador Pentium III. Para cada lâmina leram-se 3 campos com ampliação de 200 X, sobre a área da cicatriz e obteve-se a média da leitura.
Submeteram-se os resultados à estudo estatístico. Para as tabelas 2 × 2 empregou-se o teste paramétrico Qui-quadrado. Quando restrições a ele estavam presentes, empregou-se o teste, não paramétrico, Exato de Fisher. Para a comparação de médias utilizou-se o teste paramétrico $t$ de student. Quando os números analisados não constituíam curva gaussiana, este teste foi substituído pelo teste não paramétrico de Mann Whitney. Fixou-se $\mathrm{p}=0,05$ ou 5,0\% como nível para rejeição da hipótese de nulidade.

\section{Resultados}

Todos os animais sobreviveram até a data prevista para a eutanásia.

Na cicatriz da pele a média da resistência, medida em Newtons, era mínima, no $3 .^{\circ}$ dia, e semelhante em todos os grupos $(\mathrm{JN}=0,785 \pm$ $0,289 \mathrm{~N} ; \mathrm{VN}=0,646 \pm 0,208 \mathrm{~N} ; \mathrm{JH}=0,614 \pm 0,101 \mathrm{~N} ; \mathrm{VH}=0,667 \pm$ $0,162 \mathrm{~N})$. No $7 .^{\circ}$ dia existiu ganho de resistência. Nota-se que tanto as cicatrizes dos animais jovens quanto as dos velhos mostraram comportamento semelhante. Contudo as cicatrizes dos hipotireoideanos eram menos resistentes que as dos animais normais $(\mathrm{JN}=2,127 \pm 0,503 \mathrm{~N} ; \mathrm{VN}=2,258 \pm 0521 \mathrm{~N} ; \mathrm{JH}=1,496 \pm 0,183$ $\mathrm{N} ; \mathrm{VH}=1,559 \pm 0,427 \mathrm{~N})$. No $14{ }^{\circ}{ }^{\circ}$ dia a resistência das cicatrizes da pele era semelhante $(\mathrm{JN}=4,616 \pm 1,351 \mathrm{~N} ; \mathrm{VN}=3,793 \pm 1,098 \mathrm{~N} ; \mathrm{JH}$ $=3,656 \pm 0,532 \mathrm{~N} ; \mathrm{VH}=3,227 \pm 0,422 \mathrm{~N}$ ). (figura 1 ).

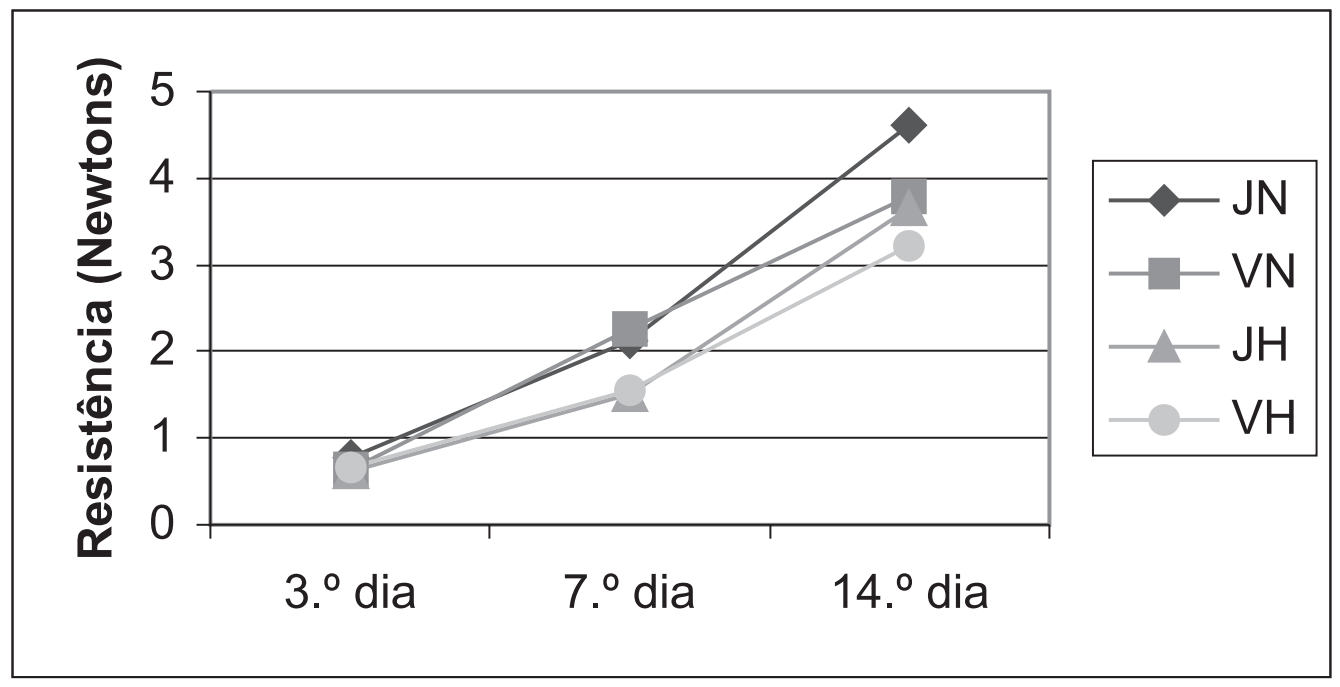

FIGURA 1 - Ganho de resistência das cicatrizes cutâneas nos 3 tempos estudados

( $\mathrm{JN}=$ jovens normais, $\mathrm{VN}=$ velhos normais, $\mathrm{JH}=$ jovens com hipotireoidismo, $\mathrm{VH}=\mathrm{velhos}$ com hipotireoidismo) Teste de Mann Whitney - 3. ${ }^{\circ}$ dia

$\mathrm{JN}$ x VN p = 0, 2280; JN x JH p =0,1830; VN x VH p=0,1300; JH x VH p =0,1970

Teste t de student $-7 .^{\circ}$ dia

JN x VN p = 0, 6410; JN x JH p= 0,0145; VN x VH p= 0,0242; JH x VH p = 0,7443

Teste t de student - $14 .^{\circ}$ dia

JN x VN p =0, 2351; JN x JH p =0,1318; VN x VH p =0,2616; JH x VH p =0,1530 
Os achados microscópicos gerais foram semelhantes em todos os grupos. No 3. ${ }^{\circ}$ dia as cicatrizes cutâneas mostravam solução de continuidade do tecido epitelial, as feridas apresentavam na superfície crosta fibrinoleucocitária e podia-se ver reepitelização marginal. Abaixo existia infiltrado de células inflamatórias com predomínio de polimorfonucleares, macrófagos e mastócitos. No $7^{\circ}$ dia, muitas feridas estavam completamente reepitelizadas, porém não existiu diferença significante entre os grupos. Abaixo encontrava-se infiltrado de células inflamatórias e abundante tecido de granulação. No $14 .^{\circ}$ dia todas as feridas estavam completamente reepitelizadas. Não se observavam anexos da pele e havia escassa reação inflamatória.

A presença de colágeno, nas cicatrizes da pele, foi menor nos animais hipotireoideanos, na avaliação do $7 .^{\circ}$ dia e não guardou relação com a idade. Na avaliação do $14 .^{\circ}$ dia a presença de colágeno foi menor nas cicatrizes dos hipotireoideanos e ainda mais nas dos animais velhos (quadro 1). Observou-se menor concentração de colágeno tipo I nas cicatrizes dos animais hipotireoideanos, tanto jovens quanto velhos no $7 .^{\circ}$ dia, sendo a baixa concentração de colágeno tipo III, mais importante, encontrada nas cicatrizes dos animais velhos analisadas com 14 dias (quadros 1, 2 e 3; figura 2).

QUADRO 1 - Média e desvio padrão do percentual da área das cicatrizes cutâneas ocupadas por colágeno, nos animais dos 4 grupos e nos 3 tempos

\begin{tabular}{|c|c|c|c|}
\hline \multirow[b]{2}{*}{ GRUPO } & \multicolumn{3}{|c|}{$\%$ da área examinada ocupado por colágeno } \\
\hline & $3 .^{\circ} \mathrm{dia}$ & 7. ${ }^{\circ} \mathrm{dia}$ & $14 .^{\circ} \mathrm{dia}$ \\
\hline Jovens normais & $11,70 \pm 2,26$ & $55,76 \pm 10,08$ & $58,19 \pm 7,49$ \\
\hline Velhos normais & $12,66 \pm 1,83$ & $60,72 \pm 5,59$ & $61,52 \pm 8,52$ \\
\hline Jovens hipotireoideanos & $11,50 \pm 3,23$ & $38,71 \pm 9,80$ & $59,91 \pm 9,14$ \\
\hline Velhos hipotireoideanos & $11,99 \pm 3,34$ & $41,25 \pm 7,85$ & $49,22 \pm 4,57$ \\
\hline \multicolumn{4}{|c|}{ 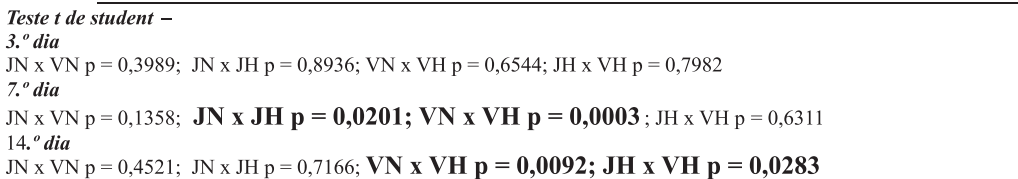 } \\
\hline
\end{tabular}

QUADRO 2 - Média e desvio padrão do percentual da área das cicatrizes cutâneas ocupadas por colágeno tipo I, nos animais dos 4 grupos e nos 3 tempos

\begin{tabular}{|c|c|c|c|}
\hline \multirow[b]{2}{*}{ GRUPO } & \multicolumn{3}{|c|}{ \% da área examinada ocupado por colágeno I } \\
\hline & $3 .^{\circ} \mathrm{dia}$ & $7 .^{\circ} \mathrm{dia}$ & $14 .^{\circ} \mathrm{dia}$ \\
\hline Jovens normais & $2,69 \pm 0,73$ & $26,88 \pm 5,85$ & $32,18 \pm 5,21$ \\
\hline Velhos normais & $3,24 \pm 0,56$ & $29,56 \pm 6,22$ & $39,91 \pm 7,13$ \\
\hline Jovens hipotireoideanos & $2,28 \pm 0,67$ & $22,75 \pm 6,91$ & $25,30 \pm 4,50$ \\
\hline Velhos hipotireoideanos & $2,75 \pm 0,67$ & $17,12 \pm 5,10$ & $32,30 \pm 6,86$ \\
\hline \multicolumn{4}{|c|}{ 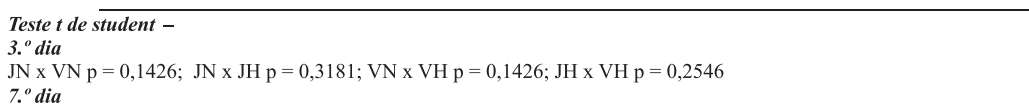 } \\
\hline \multicolumn{4}{|c|}{ 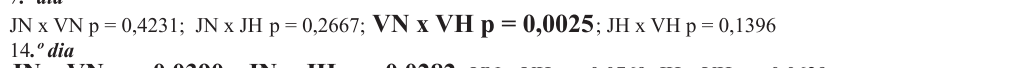 } \\
\hline
\end{tabular}

QUADRO 3 - Média e desvio padrão do percentual da área das cicatrizes cutâneas ocupadas por colágeno tipo III, nos animais dos 4 grupos e nos 3 tempos

\begin{tabular}{|c|c|c|c|}
\hline \multirow[b]{2}{*}{ GRUPO } & \multicolumn{3}{|c|}{ \% da área examinada ocupado por colágeno III } \\
\hline & 3. ${ }^{\circ}$ dia & 7. ${ }^{\circ}$ dia & $14 .^{\circ}$ dia \\
\hline Jovens normais & $9,01 \pm 1,99$ & $26,88 \pm 9,29$ & $26,01 \pm 8,35$ \\
\hline Velhos normais & $9,43 \pm 1,45$ & $31,16 \pm 7,14$ & $21,61 \pm 6,29$ \\
\hline Jovens hipotireoideanos & $9,22 \pm 3,20$ & $15,97 \pm 3,70$ & $34,61 \pm 7,12$ \\
\hline Velhos hipotireoideanos & $9,25 \pm 2,99$ & $24,13 \pm 7,23$ & $19,99 \pm 7,52$ \\
\hline \multicolumn{4}{|c|}{$\begin{array}{l}\text { Teste t de student - } \\
\text { 3. }{ }^{\circ} \text { dia } \\
\mathrm{JN} \times \mathrm{VN} \mathrm{p}=0,6661 ; \mathrm{JN} \times \mathrm{JH} \mathrm{p}=0,8918 ; \mathrm{VN} \times \mathrm{VH} \mathrm{p}=0,8899 ; \mathrm{JH} \times \mathrm{VH} \mathrm{p}=0,9870 \\
7^{\circ} \text { dia }\end{array}$} \\
\hline
\end{tabular}




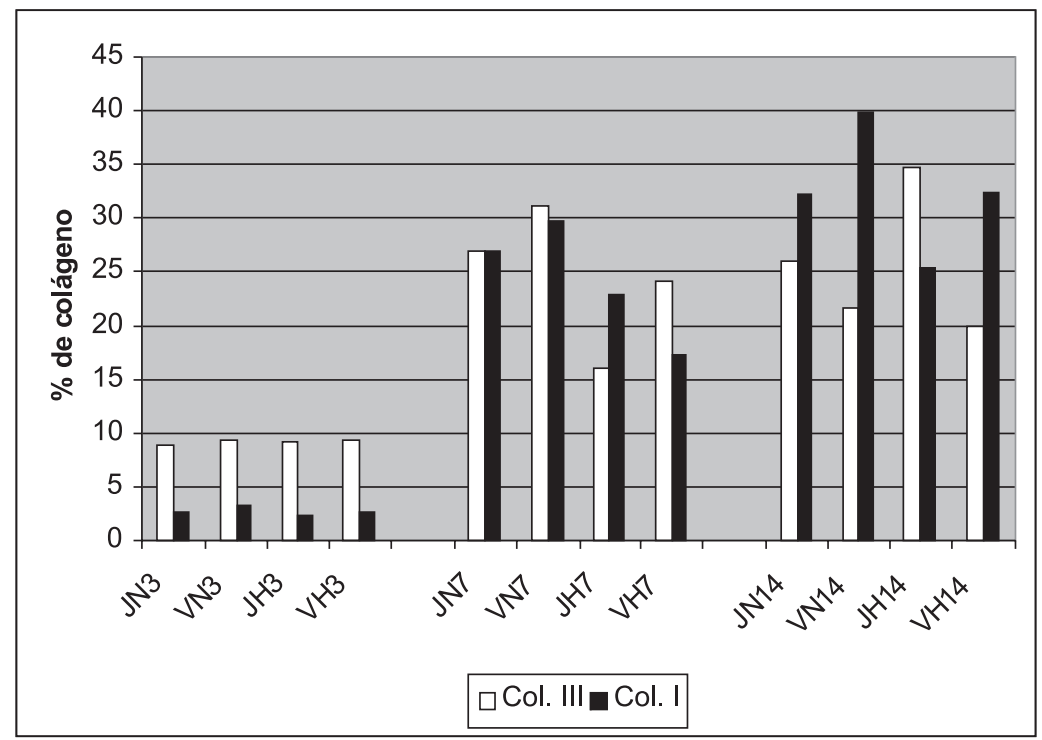

FIGURA 2 - Média do percentual das áreas das cicatrizes cutâneas ocupadas por colágeno I e III, no 3. $.^{\circ}, 7 .^{\circ}$ e $14 .^{\circ}$ dias ( $\mathrm{JN}=$ jovens normais, $\mathrm{VN}=$ velhos normais, $\mathrm{JH}=$ jovens com hipotireoidismo, $\mathrm{VH}=$ velhos com hipotireoidismo)

No plano peritônio-músculo-aponevrótivo a média da resistência era mínima no $3 .^{\circ}$ dia $(\mathrm{JN}=1,179 \pm 0,401 \mathrm{~N} ; \mathrm{VN}=$ $1,062 \pm 0,364 \mathrm{~N} ; \mathrm{JH}=1,263 \pm 0,456 \mathrm{~N} ; \mathrm{VH}=1,058 \pm 0,471$ N). No $7 .^{\circ}$ dia observou-se ganho de resistência, porém não existiu diferença significante entre os grupos $(\mathrm{JN}=$ $2,135 \pm 0,444 \mathrm{~N} ; \mathrm{VN}=2,091 \pm 0,601 \mathrm{~N} ; \mathrm{JH}=2,136 \pm 0,466 \mathrm{~N}$; $\mathrm{VH}=1,638 \pm 0,749 \mathrm{~N})$. No $14 .^{\circ}$ dia verificou-se que as cicatrizes dos animais velhos eram mais resistentes do que as dos animais jovens $(\mathrm{p}=0,0014)$, porém quando hipotireoidismo estava associado, as cicatrizes dos animais velhos eram mais frágeis do que as dos velhos normais
$(\mathrm{p}=0,0000)(\mathrm{JN}=3,365 \pm 0,693 \mathrm{~N} ; \mathrm{VN}=4,810 \pm 0,509 \mathrm{~N} ; \mathrm{JH}$ $=3,256 \pm 0,636 \mathrm{~N} ; \mathrm{VH}=2,778 \pm 0,471 \mathrm{~N}$ ). (figura 3).

As feridas peritônio-músculo-aponevróticas mostravam solução de continuidade nos 4 grupos de animais e nos 3 tempos estudados. No $3 .^{\circ}$ dia havia infiltrado de células inflamatórias e escasso tecido de granulação. No $7 .^{\circ}$ dia podia-se encontrar abundante tecido de granulação, fibroblastos e neovasos. No 14. ${ }^{\circ}$ dia a reação inflamatória era do tipo agudo-crônica e o tecido de granulação abundante. Nas margens interna e externa da ferida encontrava-se grande quantidade de colágeno.

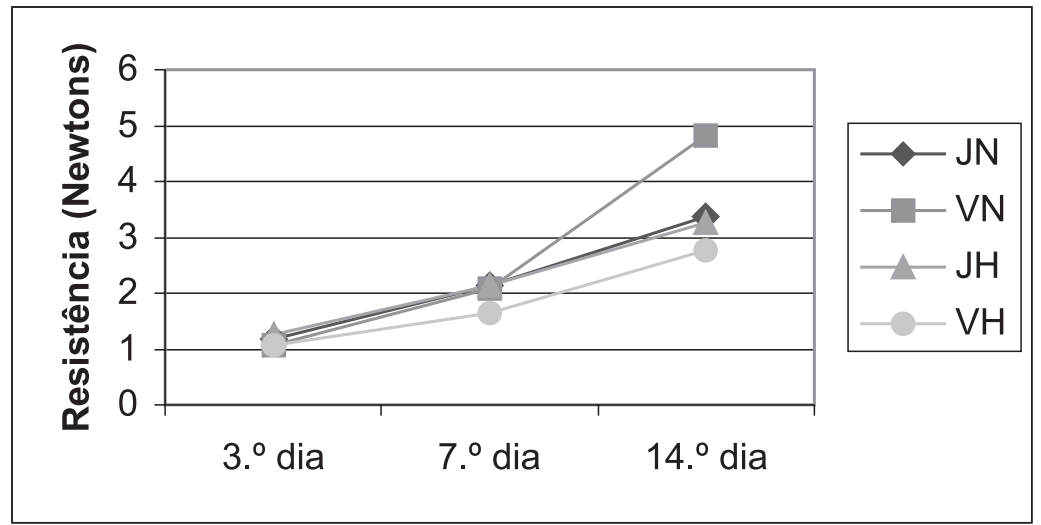

FIGURA 3 - Ganho de resistência das feridas do plano peritônio-músculo-aponevrótico

( $\mathrm{JN}=$ jovens normais, $\mathrm{VN}=$ velhos normais, $\mathrm{JH}=$ jovens com hipotireoidismo, $\mathrm{VH}=$ velhos com hipotireoidismo) Teste de Mann Whitney - 3. ${ }^{\circ}$ dia

$\mathrm{JN} \times \mathrm{VN} \mathrm{p}=0,2280 ; \mathrm{JN}$ x JH p =0,4730; VN x VH p =0,3650; JH x VH p =0,1970

Teste de Mann Whitney - 7. ${ }^{\circ}$ dia

$\mathrm{JN}$ x VN p =0,5000; JN x JH p =0,5270; VN x VH p =0,1470; JH x VH p =0,1200

Teste t de student $-14 .^{\circ}$ dia

JN x VN p = 0,0014; JN x JH p = 0,5834; VN x VH p = 0,0000; JH x VH p = 0,1700 
A presença de colágeno foi menor nas cicatrizes do plano peritônio-músculo-aponevrótico dos animais hipotireoidianos, independente da idade, em todos os tempos. No $7 .^{\circ}$ dia observou-se relação com o hipotireoidismo e com a idade o mesmo acontecendo no $14 .^{\circ}$ dia (quadro 4). Verificou-se, no $7 .^{\circ}$ dia baixa concentração de colágeno tipo I, de forma significante nas cicatrizes dos animais velhos com hipotireoidismo ( $\mathrm{p}=0,0077)$. Já no $14{ }^{\circ}$ dia, a concentração desta fração de colágeno era menor nas cicatrizes dos animais velhos hipotireoideano quando comparados aos velhos normais $(0,00033)$ e guardava relação com a idade ( $\mathrm{p}=0,0081$ ) (quadro 5). A concentração de colágeno III, no 3. ${ }^{\circ}$ dia, era menor nas cicatrizes dos animais hipotireoideanos, tanto nas feridas dos animais jovens $(\mathrm{p}=0,0150)$ quanto nas dos velhos $(\mathrm{p}=0,0370)$. Isto persistiu no $14 .^{\circ}$ dia $(\mathrm{JN} \times \mathrm{JH} \mathrm{p}=$ 0,0015; (VN x VH p = 0,0067) (quadro 6). A figura 4 concentra todas as informações da presença de colágeno nos 3 tempos estudados.

QUADRO 4 - Média e desvio padrão do percentual da área da cicatriz do plano peritônio-músculo-aponevrótico ocupada por colágeno, nos animais dos 4 grupos e nos 3 tempos

\begin{tabular}{|c|c|c|c|}
\hline \multirow[b]{2}{*}{ GRUPO } & \multicolumn{3}{|c|}{ \% da área examinada ocupado por colágeno } \\
\hline & $3 .^{\circ} \mathrm{dia}$ & 7..$^{\circ}$ dia & $14 .^{\circ}$ dia \\
\hline Jovens normais & $17,04 \pm 3,62$ & $59,53 \pm 4,09$ & $69,18 \pm 10,75$ \\
\hline Velhos normais & $16,80 \pm 4,98$ & $54,39 \pm 4,40$ & $64,89 \pm 8,09$ \\
\hline Jovens hipotireoideanos & $11,08 \pm 3,06$ & $39,28 \pm 7,00$ & $58,72 \pm 3,74$ \\
\hline Velhos hipotireoideanos & $10,41 \pm 2,67$ & $38,73 \pm 5,75$ & $43,24 \pm 7,86$ \\
\hline \multicolumn{4}{|c|}{ 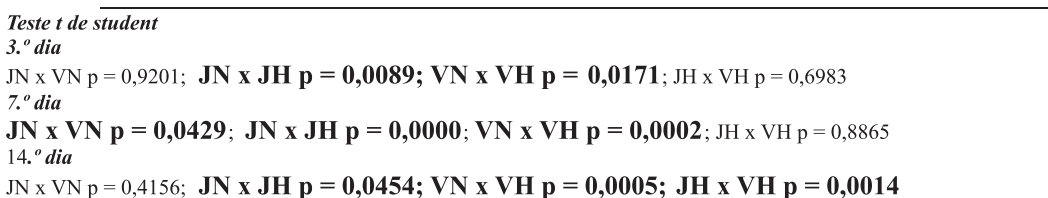 } \\
\hline
\end{tabular}

QUADRO 5 - Média e desvio padrão do percentual da área da cicatriz do plano peritônio-músculo-aponevrótico ocupada por colágeno tipo I, nos animais dos 4 grupos e nos 3 tempos

\begin{tabular}{|c|c|c|c|}
\hline \multirow[b]{2}{*}{ GRUPO } & \multicolumn{3}{|c|}{ \% da área examinada ocupado por colágeno I } \\
\hline & 3. ${ }^{\circ} \mathrm{dia}$ & 7..$^{\mathrm{dia}}$ & $14 .^{\circ} \mathrm{dia}$ \\
\hline Jovens normais & $3,06 \pm 0,81$ & $22,02 \pm 7,91$ & $46,67 \pm 13,59$ \\
\hline Velhos normais & $3,26 \pm 0,82$ & $19,89 \pm 7,12$ & $46,32 \pm 7,53$ \\
\hline Jovens hipotireoideanos & $2,55 \pm 0,66$ & $18,33 \pm 2,14$ & $39,99 \pm 7,96$ \\
\hline Velhos hipotireoideanos & $2,64 \pm 0,60$ & $13,84 \pm 2,53$ & $26,20 \pm 6,41$ \\
\hline \multicolumn{4}{|c|}{ 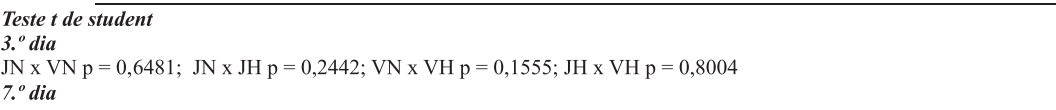 } \\
\hline
\end{tabular}

QUADRO 6 - Média e desvio padrão do percentual da área da cicatriz do plano peritônio-músculo-aponevrótico ocupada por colágeno tipo III, nos animais dos 4 grupos e nos 3 tempos

\begin{tabular}{|c|c|c|c|}
\hline \multirow[b]{2}{*}{ GRUPO } & \multicolumn{3}{|c|}{ \% da área examinada ocupado por colágeno III } \\
\hline & $3 .^{\circ} \mathrm{dia}$ & $7 .^{\circ} \mathrm{dia}$ & $14 .^{\circ} \mathrm{dia}$ \\
\hline Jovens normais & $13,98 \pm 3,32$ & $37,48 \pm 7,69$ & $22,51 \pm 9,60$ \\
\hline Velhos normais & $7,77 \pm 2,52$ & $34,50 \pm 5,12$ & $19,58 \pm 8,40$ \\
\hline Jovens hipotireoideanos & $8,52 \pm 3,25$ & $20,94 \pm 6,36$ & $18,78 \pm 6,11$ \\
\hline Velhos hipotireoideanos & $6,77 \pm 2,26$ & $24,89 \pm 5,25$ & $17,04 \pm 3,14$ \\
\hline \multicolumn{4}{|c|}{$\begin{array}{l}\text { Teste de Mann Whitney } \\
3^{3}{ }^{\circ} \text { dia }\end{array}$} \\
\hline \multicolumn{4}{|c|}{ 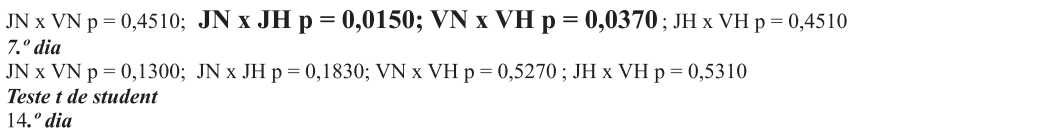 } \\
\hline
\end{tabular}




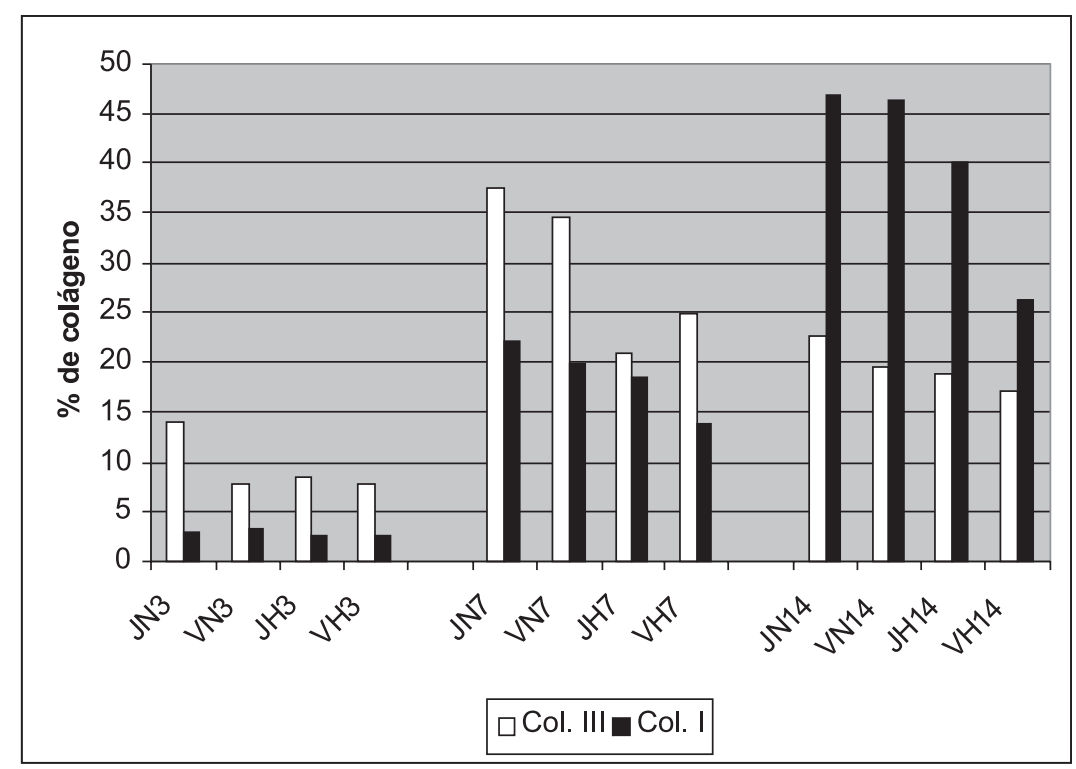

FIGURA 4 - Representação gráfica das médias da percentagem da área da cicatriz do plano peritônio-músculo-aponevrótico ocupada por colágeno nos 3 tempos estudados, nos 4 grupos

( $\mathrm{JN}=$ jovens normais, $\mathrm{VN}=$ velhos normais, $\mathrm{JH}=$ jovens com hipotireoidismo, $\mathrm{VH}=\mathrm{velhos}$ com hipotireoidismo)

\section{Discussão}

O aumento da vida média levou a aumento do número de intervenções em idosos. Muitos cirurgiões acreditam que a idade avançada produza modificações fisiológicas que comprometem a cicatrização.

Alguns estudos clínicos multicêntricos apontam a idade como fator de risco para a cicatrização ${ }^{1,2}$ e pesquisadores demonstraram, em idosos, atraso de epitelização e baixa da concentração de colágeno, tanto do tipo I, quanto do tipo III $^{7,8}$. Em estudo recente de nossa linha de pesquisa, observou-se atraso da deposição destes tipos de colágeno, em ratos velhos ${ }^{23}$.

Parece que fibroblastos senescentes respondem menos a estímulos mitogênicos ${ }^{9}$, porém não existem evidências de que a resposta de fibroblastos humanos aos fatores de crescimento, seja afetada pela idade ${ }^{10}$.

A atenção para o estado de hipotireoidismo afetando a cicatrização inicia com os relatos de ALEXANDER et al que observaram que pacientes laringectomizados, após radioterapia, desenvolviam fístulas e que isto estava relacionado ao hipotireoidismo desencadeado pela radioterapia e que quando administravam hormônio tireoideano aos doentes, esta complicação deixava de existir. Anteriormente autores haviam dito que o hipotireoidismo diminuía a síntese de colágeno e interferia no seu metabolismo ${ }^{(4,14)}$.

Descreveu-se, em modelo experimental em camundongos, envolvimento direto do hormônio tireoideano na modulação da expressão do gen para o colágeno I identificaram-se mecanismos moleculares envolvidos na indução do hormônio tireodeano regulando o RNA mensageiro para o colágeno I. O hipotireoidismo levaria à inibição da síntese do colágeno, mostrado pela falta de fibrose induzindo à hipertrofia ventricular esquerda e baixa concentração do colágeno intracelular nos fibroblastos cardíacos ${ }^{16}$. Recentemente relatou-se que na reparação de fraturas, de ratos com hipotireoidismo existia diminuição da ossificação endocondral, intramembranossa e da condrogênese ${ }^{18}$.

Já havia sido observado, em estudo experimental feito com ratos com hipotireoidismo induzido com 5-propil,2-thiuracil, diminuição da resistência das cicatrizes abdominais $(\mathrm{p}<0,001)$ e da concentração de hidroxiprolina $(\mathrm{p}<0,001)$, mas apenas nas observações do $14 .^{\circ}$ dia. A resistência seria dependente tanto da quantidade de colágeno quanto da organização, visto que nas cicatrizes dos ratos com hipotireoidismo encontraram, não só diminuição da concentração de colágeno mas, também atraso da organização ${ }^{17}$.

Existe relato da diminuição do conteúdo de colágeno IV em pacientes com hipotireoidismo ${ }^{19}$. Em ratos com hipotireoidismo cirúrgico, descreveram-se feridas abdominais com importante diminuição da concentração de hidroxiprolina no $7 .^{\circ}$ dia $(\mathrm{p}<0,05)$ e no $14 .^{\circ}$ dia $(\mathrm{p}<0,01)$ além do declínio do colágeno IV em todos os tempos $(\mathrm{p}<0,02)$. O hormônio tireoideano está associado com a proliferação e a secreção dos fibroblastos. A supressão da secreção dos hormônios tireoideanos causaria distúrbio da ativação metabólica nos tecidos e na síntese do colágeno, se estendendo da fase inflamatória até a fase proliferativa. Sugeriram que o hormônio tireoideano estaria associado com a proliferação e a secreção dos fibroblastos ${ }^{20}$.

O envelhecimento determina reações que alteram o "status" tireoideano, sendo relativamente freqüente, o estado de hipotireoidismo. Segundo relatos de Oliveira ${ }^{21}$, em levantamento que deu origem à sua tese, $24,1 \%$ dos pacientes idosos apresentam hipotireoidismo. Schindler salientou que o avan- 
çar da idade aumenta a possibilidade de hipofunção tireoideana, especialmente nas mulheres. Segundo este autor após a menopausa $2,4 \%$ das mulheres apresentam clínica de disfunção e 23,2\% têm doença subclínica.

Devemos lembrar que os estudos aqui relatados, abordavam ora idosos, ora hipotireoideanos e que as 2 situações não foram tratadas simultaneamente.

Em estudo de nossa linha de pesquisa observou-se que, embora existam diferenças no processo de cicatrização de jovens e velhos, a idade, por si só, não é a causa da falência da cicatrização, tanto nas feridas da parede abdominal, quanto nas das anastomoses colônicas ${ }^{23}$. Neste estudo, verificou-se que a resistência da cicatriz cutânea estava influenciada pelo hipotireoidismo, mas não pela idade avançada dos animais, no início do processo de cicatrização, o mesmo acontecendo com a concentração do colágeno. Nas cicatrizes avaliadas mais tardiamente, observou-se que os idosos tinham menos colágeno do que os jovens. Um dado interessante foi obtido das cicatrizes peritônio-músculo-aponevróticas dos animais idosos normais, que mostraram mais resistentes nas avaliações tardias quando comparadas às dos jovens. Entretanto, a concentração de colágeno nas cicatrizes dos idosos com hipotireoidismo era muito mais baixa que a encontrada nas dos jovens normais ou nos jovens com hipotireoidismo, demonstrando que o hipotireoidismo era um fator que influenciava negativamente a resistência. O conteúdo de colágeno mostrou-se menos influenciado pela idade avançada do que pelo hipotireoidismo. Entretanto idade e hipotireoidismo associados, prejudicavam tanto a resistência quanto a presença de colágeno, tanto nas cicatrizes da pele quanto nas do plano peritônio-músculo-aponevrótico.

\section{Conclusão}

A análise dos resultados permite concluir que existe prejuízo da cicatrização na presença de hipotireoidismo que é piorada com o envelhecimento.

\section{Referências}

1. Riou JP, Cohen JR, Johnson H. Factors influencing wound dehiscense. Am J Surg 1992; 163:324-30.

2. Carlson MA. Acute wound failure. Surg Clin North Am 1997; 77:607-36.

3. Gromakova IA, Zilberman ST, Konovalenko AO. Age-related changes of protein- and RNA synthetic processes in experimental hyper- and hipothyroidism. Biochemistry (Mosc) 2001; 66:763-8.

4. Kivirikko KI, Laitinen O, Aer J, Halme J. Metabolism of collagen in experimental hyperthyroidism and hypothyroidism in the rat. Endocrinology 1967:80:1051-61.

5. Gilchrest BA. In vitro assessment of keratinocyte aging. J Invest Dermatol 1983; 81(1 Suppl):184s-189s.
6. Holt DR, Kirk SJ, Regan MC, Hurson M, Lindblad WJ, Barbul A. Effect of age on wound healing in healthy human beings. Surgery 1992; 112:293-8.

7. Ashcroft GS, Kielty CK, Horan MA, Ferguson MW. Age-related changes in the temporal and spatial distribitions of fibrilin and elastin mRNAs and proteins in acute cutaneous wounds of healthy humans. J Pathol 1997; 183:80-9.

8. Reed MJ, Corsa A, Pendergrass W, Penn P, Sage EH, Abrass IB. Neovascularization in aged mice: delayed angiogenesis is coincident with decreased levels of transforming growth factor beta 1 and type I collagen. Am J Pathol 1998; 152:113-23.

9. Cristofalo VJ, Pignolo RJ. Replicative senescence of human fibroblast like cells in culture. Physiol Rev 1993; 73:617-38.

10. Kletsas D, Pratsinis H, Zervolea I, Handris P, Sevaslidou E, Ottaviani E, Stathakos D. Fibroblast responses to exogenous and autocrine factors relevant to tissue repair: the effect of aging. Ann N Y Acad Sci 2000; 908:155-66.

11. Alexander MV, Zajtchuk JT, Henderson RL. Hypothyroidism and wound healing. Arch Otolaryngol 1982; 108:289-91.

12. Cannon CR. Hypothyroidism in head and neck cancer patients: experimental and clinical observations. Laryngoscope 1994; 104(11Pt 2 Suppl 66):1-21.

13. Sterling K. Thyroid hormone action at thye cell level. N Engl J Med 1979; 300:117-23.

14. Kowalewski K, Yong S. Hydroxyproline in healing dermal wounds of normal and hypothyroid rats. Acta Endocrinol 1967; 54:1-7.

15. Yao J, Eghbali M. Decreased collagen mRNA and regression of cardiac fibrosis in the ventricular myocardium of the tight skin mouse following thyroid hormone treatment. Cardiovasc Res 1992; 26:603-7.

16. Lee HW, Klein LE, Raser J, Eghbali-Webb M. An activator protein1 (AP-1) response element on pro alpha (1) collagen gene is necessary for thyroid hormon-induced inhibition for promoter activity in cardiac fibroblasts. J Mol Cell Cardiol 1998; 30:2495-506.

17. Erdogan M, Ilhan YS, Akkus MA, Caboglu AS, Ozercan I, Ilhan N, Yaman M. Effects of L-thyroxine and zinc therapy on wound healing in hypothyroid rats. Acta Chir Belg 1999; 99:72-7.

18. Urabe K, Hotokebuchi T, Oles KJ, Bronk JT, Jingushi S, Iwamoto Y, Bolander ME. Inhibiton of endochondral ossification during fracture repair in experimental hypotiroid rats. J Orthop Res 1999; 17:920-5.

19. Senda Y, Nishibu M, Kawai K, Mizukami Y, Hashimoto T. Evaluation of type IV collagen in patients with various thyroid disease. Rinsko Byori 1993; 41:1338-42.

20. Natori J, Shimizu K, Nagahama M, Tanaka S. The influence of hypothyroidism on wound healing. J Nippon Med Sch 1999; 66:176-80.

21. Oliveira ILC. Avaliação das funções tireóideas em idosos. [Tesedoutorado]. Salvador: Universidade Federal da Bahia; 1998.

22. Schindler AE. Thyroid function and postmenopause. Gynecol Endocrinol 2003; 17:79-85. 
23. Biondo-Simões MLP. Os efeitos do envelhecimento na cicatrização: avaliação da parede abdominal e de anastomoses colônicas, em ratos. 2001. Curitiba, 168p (Tese - Professor Titular - Pontifícia Universidade Católica do Paraná).
24. Junqueira LCU, Bignolas G, Brentani RR. Picrosirius staining plus polarization microscopy, a specific method for collagen detection in tissue sections. Histochem J 1979;11:447-55.

Biondo-Simões MLP, Ioshii SO, Borsato KS, Zimmermann E. The healing process inffluenced by hypotireoidism and by elderly. Study of abdominal wall healing in rats. Acta Cir Bras [serial on line] Available from: URL: htt://www.scielo.br/acb.

ABSTRACT - Purpose: Hypothyroidism is a common situation among the aged which affects protein synthesis. The objective of the present study was to determine the influence of hypothyroidism on the healing process in aged rats. Methods: 96 male Wistar rats were used, 48 of them with a mean age of 110 days and 48 with a mean age of 750 days. Half the young animals and half the old ones were euthyroid and half were hypothyroid. Hypothyroidism was obtained by total thyroidectomy. Thirty days after surgery the animals were submitted to median laparotomy followed by laparorrhaphy on 2 synthesis planes. Six animals from each group were submitted to euthanasia by drawing lots on the $3^{\text {rd }}, 7^{\text {th }}$ and $14^{\text {th }}$ postoperative day and submitted to macroscopic, resistance, and histopathological analysis. Results: The resistance of the skin scars was lower in hypothyroid animals, both the young $(\mathrm{p}=0.0145)$ and old ( $\mathrm{p}=0.0242$ ) ones, with no significant relation with age being detected. The resistance of the scars on the peritoneum-muscleaponeurosis plane was lower in old animals on the 24 th day $(\mathrm{p}=0.0014)$ and even lower in hypothyroid old animals $(\mathrm{p}=0.0000)$. The histological evolution was similar, but differences in collagen presence were observed. On the $7^{\text {th }}$ day the skin scars had a lower collagen content in young $(\mathrm{p}=0.0201)$ and old $(\mathrm{p}=0.0003)$. hypothyroid animals. On the 14 th day the scars of old hypothyroid animals had less collagen than those of normal old animals $(\mathrm{p}=0.0092)$ and those of young hypothyroid animals $(\mathrm{p}=0.0283)$. On the $3^{\text {rd }}$ day, the scars of hypothyroid animals on the peritoneum-muscle-aponeurosis plane presented less collagen than those of both young $(\mathrm{p}=0.0089)$ and old $(\mathrm{p}=0.0171)$ normal controls, but there was no relation with age. This association persisted on the $7^{\text {th }}$ and $17^{\text {th }}$ day, but age dependence was observed at these time points. Conclusion: Analysis of the results permits us to conclude that healing is impaired in the presence of hypothyroidism and worsens with aging.

KEYWORDS: Wound healing. Collagen. Hypothyroidism. Aging.

Correspondência:

Rua Ari José Valle, 1987, Santa Felicidade

CEP 82030-000, Curitiba-Paraná

Telefone 0XX41.297.43.59

e-mail: biondo@avalon.sul.com.br 